\title{
Effects of sodium cromoglycate and nedocromil sodium on histamine secretion from human lung mast
} cells

\author{
K B P LEUNG, K C FLINT, J BROSTOFF, B N HUDSPITH, N MCI JOHNSON, \\ H Y A LAU, W L LIU, F L PEARCE \\ From the Department of Chemistry, University College London, and the Medical Unit and Department of \\ Immunology, Middlesex Hospital Medical School, London
}

ABSTRACT Sodium cromoglycate and nedocromil sodium produced a dose dependent inhibition of $-\overrightarrow{-}$ histamine secretion from human pulmonary mast cells obtained by bronchoalveolar lavage and by요 enzymatic dissociation of lung parenchyma. Both compounds were significantly more active against the lavage cells than against the dispersed lung cells, and nedocromil sodium was an order of magnitude more effective than sodium cromoglycate against both cell types. Tachyphylaxis was $\vec{\oplus}$ observed with the parenchymal cells but not with the lavage cells. Nedocromil sodium and sodium ${ }^{\infty}$ cromoglycate also inhibited histamine release from the lavage cells of patients with sarcoidosis and extrinsic asthma.

\section{Introduction}

Asthma is a complex, multifactorial disease characterised by non-specific bronchial hyperreactivity and inflammation of the airways. It is now clear that several cell types and chemical mediators may participate in its pathogenesis and that the inflammatory response is the result of an intricate interaction between these agents. ${ }^{2}$ No single cell type appears to be responsible for all the manifestations of asthma, though activation of pulmonary mast cells has long been considered to be central to the early stages of the disease process. Mast cells are widely distributed throughout the human respiratory tract and those lying within or immediately adjacent to the mucosal surface of the airways might be expected to be of greater importance in the initial phase of the allergic response. These cells would come into direct contact with inhaled antigens and release their mediators locally on to the airway surface. More deeply situated mast cells and other inflammatory cells may play an increasing part in the development of the chronic disease, damage to the mucosal barrier and respiratory epithelium allowing increased penetration of inhaled antigen.

Address for reprint requests: Dr F L Pearce, Department of Chemistry, University College London, London WC1H 0AJ.

Accepted 21 July 1988
Superficially located mast cells can be recovered by $\stackrel{2}{\circ}$ bronchoalveolar lavage and parenchymal mast cells $\stackrel{\varrho}{\square}$ by enzymatic dissociation of lung tissue..$^{3-7}$ We haveō shown functional differences between these cell types 3 and variation in their responsiveness to various secretory stimuli and to anti-asthma drugs. ${ }^{3-7}$ Studies in rodents suggest that murine mucosal mast cells $\vec{\partial}$ represent a subpopulation of cells with pharmaco- $\frac{O}{\partial}$ logical properties that are distinct from those of the cells in the connective tissues. ${ }^{8-10}$ In view of the potential clinical importance of mast cell heterogeneity and the considerable tissue and species 3 specificity of many anti-asthma drugs, ${ }^{910}$ we have now examined the effects of sodium cromoglycate and its? more potent congener nedocromil sodium on humano pulmonary mast cells obtained by lavage and from lung parenchyma.

\section{Methods}

\section{BRONCHOALVEOLAR LA VAGE}

Bronchoalveolar lavage was initially performed as? previously described ${ }^{3}$ on non-asthmatic, non-atopic patients undergoing bronchoscopy for routine diagnostic purposes.

After sedation bronchoscopy was carried out with $\stackrel{0}{\mathbb{D}}$ an Olympus BF 1TR fibreoptic bronchoscope under $\frac{\text { Pे }}{2}$ local anaesthesia with lignocaine. Lavage was perfor-음 med in the medial segments of the left lower lobe of the lung opposite to the lung affected by any localised 
bronchoscopic or radiological abnormality. Lavage was carried out with prewarmed buffered saline $(3 \times$ $60 \mathrm{ml})$ and the cells were recovered by centrifugation $\left(200 \mathrm{~g}, 5 \mathrm{~min}, 4^{\circ} \mathrm{C}\right)$ and washed for experimental use.

Subsequently, lavage was carried out on subjects with extrinsic asthma and patients with biopsy proved sarcoidosis. The asthmatic subjects had one or more positive skin reactions to prick tests with 10 common inhalant antigens and medication was withdrawn before the lavage as previously described. ${ }^{4}$ The diagnosis of sarcoidosis was based on previously defined criteria. ${ }^{5}$ None of the patients was receiving steroids at the time of the study.

\section{PARENCHYMAL MAST CELLS}

Macroscopically normal lung tissue obtained from patients during surgery for carcinoma of the bronchus was dissected free of major airways, blood vessels, and pleura and chopped mechanically into fragments. The latter were dispersed into their component cells by treatment with the enzyme collagenase. ${ }^{6}$

\section{FUNCTIONAL STUDIES}

Aliquots of cells $\left(200 \mu \mathrm{l}\right.$ containing $2 \times 10^{6}$ dispersed lung cells or $2-5 \times 10^{6}$ lavage cells) were allowed to

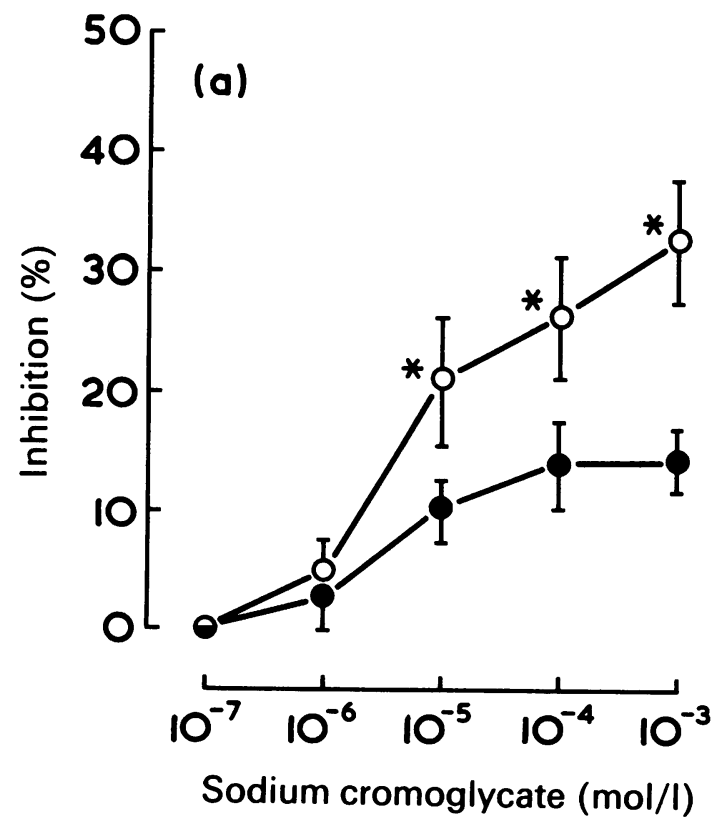

equilibrate at $37^{\circ} \mathrm{C}$ and then activated with antihuman IgE (Seward Laboratory, London, or Dako Immunoglobulins Ltd, Copenhagen) typically at a 100 fold final dilution. The reaction was allowed to proceed for 10 minutes and then stopped by the addition of ice cold buffer $(800 \mu \mathrm{l})$. Cells and supernatants were separated by centrifugation $(100 \mathrm{~g}, 2 \mathrm{~min}$, $4^{\circ} \mathrm{C}$ ) and the histamine content in each fraction was determined spectrofluorimetrically with an automated apparatus (Technicon Autoanalyser II). Histamine release was expressed as a percentage of the total and corrected for the spontaneous release in the absence of any stimulus. Sodium cromoglycate and nedocromil sodium (both gifts from Mr P Sheard, pharmaceuticals division of Fisons PLC) were either preincubated with the cells for the stated periods of time or added simultaneously with the secretory stimulus.

Results were expressed as the percentage inhibition of the immunologically induced histamine release and thus given by the ratio [(histamine release in the absence of drug - histamine release in the presence of drug)/(histamine release in the absence of drug)] $x$ 100 . All values are given as means with standard errors in parentheses for the experiments performed. Each experiment represents an independent study on cells from a single donor.

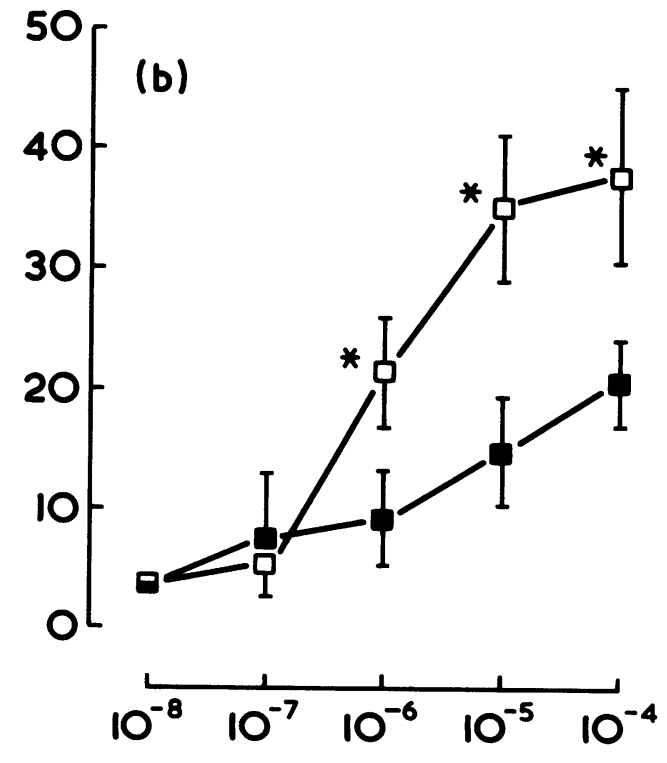

Nedocromil sodium ( $\mathrm{mol} / \mathrm{l})$

Fig 1 Effect of (a) sodium cromoglycate and (b) nedocromil sodium on immunologically induced histamine release from dispersed human lung mast cells. The drugs were added to the cells simultaneously with the secretory stimulus (open symbols) or preincubated with the cells for 10 minutes before challenge (filled symbols). The same pool of cells was used to construct the four dose-inhibition curves in each experiment. Values are means and standard errors for 10 experiments. The control immunologically induced release of histamine was $24.8 \%$ (SEM 4.9\%) of the total. ${ }^{*} p<0.05$ (paired t test). 
Results

Both sodium cromoglycate and nedocromil sodium produced dose dependent inhibition of immunologically stimulated histamine secretion from dispersed human lung mast cells, though the effect was only seen clearly when the drugs were added simultaneously with the secretory stimulus. The activity of the compounds decreased sharply on preincubation with the cells and the maximum inhibition observed after 10 minutes' pretreatment did not generally exceed $15 \%$ for sodium cromoglycate or $20 \%$ for nedocromil sodium (fig 1). A different pattern was observed with the lavage cells, where the activity of the drugs was unaffected by preincubation or if anything slightly increased (fig 2). This effect was confirmed in six additional lavage samples with two selected, intermediate drug concentrations (table). In each case the activity of the drugs was unaffected by preincubation with the lavage cells.

The relative activities of sodium cromoglycate and nedocromil sodium were compared in parallel experiments in five studies using lavage cells and in eight using dispersed lung cells (fig 3 ). In each case
Effect of preincubation time on the inhibition by sodium cromoglycate and nedocromil sodium of immunological histamine release from lavage cells in six experiments

\begin{tabular}{|c|c|c|c|}
\hline \multirow{2}{*}{$\begin{array}{l}\text { Drug and } \\
\text { concentration } \\
\text { (mol/l) }\end{array}$} & \multicolumn{2}{|c|}{ Inhibition (mean (SEM) \%) } & \multirow[b]{2}{*}{$p$} \\
\hline & $\begin{array}{l}\text { No pre- } \\
\text { incubation }\end{array}$ & $\begin{array}{l}10 \text { min pre- } \\
\text { incubation }\end{array}$ & \\
\hline $\begin{array}{l}\text { Sodium cromoglycate } \\
10^{-4} \\
10^{-5}\end{array}$ & $\begin{array}{l}23.2(7 \cdot 7) \\
14.0(8 \cdot 7)\end{array}$ & $\begin{array}{l}20 \cdot 0(4 \cdot 3) \\
16 \cdot 5(4 \cdot 2)\end{array}$ & $\begin{array}{l}0.57 \\
0.73\end{array}$ \\
\hline $\begin{array}{l}\text { Nedocromil sodium } \\
10^{-4} \\
10^{-5}\end{array}$ & $\begin{array}{l}22 \cdot 1(6 \cdot 1) \\
25 \cdot 0(7 \cdot 2)\end{array}$ & $\begin{array}{l}26 \cdot 7(5 \cdot 0) \\
23 \cdot 1(6.3)\end{array}$ & $\begin{array}{l}0.23 \\
0.51\end{array}$ \\
\hline
\end{tabular}

The control immunologically induced release of histamine was $\vec{\circ}$ $36.5 \%(4.6 \%)$ of the total. P values compare the inhibition with and without preincubation for each drug. In this experiment there was no significant difference, with or without preincubation, between the inhibition produced by equivalent concentrations of sodium $\mathrm{O}$ cromoglycate and nedocromil sodium $(p>0 \cdot 1)$.

nedocromil sodium was one order of magnitude more potent than sodium cromoglycate. Both drugs were considerably more active against the lavage cells than $\oplus_{\infty}$ against the dispersed lung cells. In 10 experiments. using carefully matched levels of immunologically
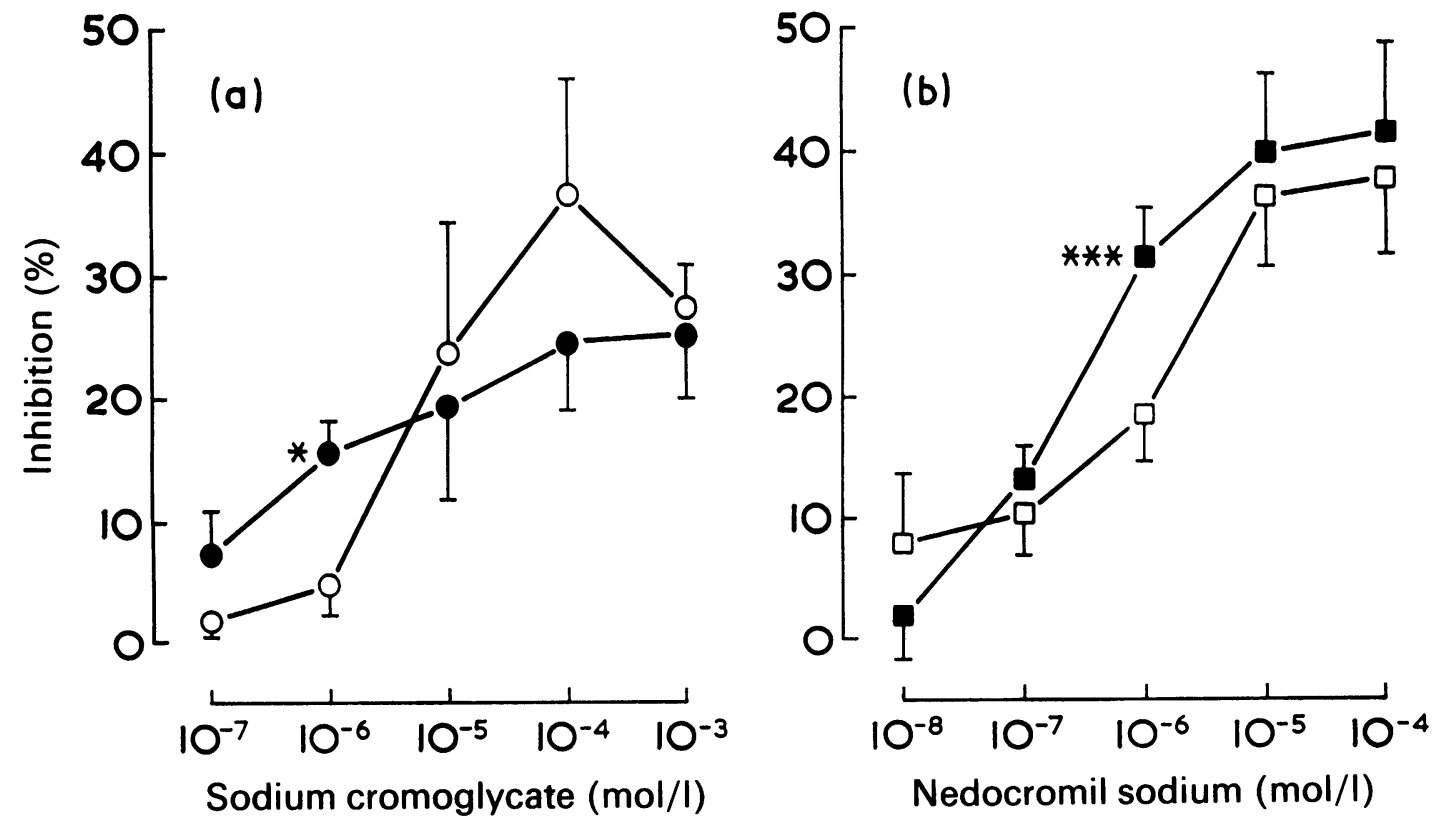

Fig 2 Effect of $(a)$ sodium cromoglycate and $(b)$ nedocromil sodium on immunologically induced histamine release from human lavage fluid mast cells. The drugs were added to the cells simultaneously with the secretory stimulus (open symbols) or preincubated with the cells for 10 minutes before challenge (filled symbols). The same pool of cells was used to construct both dose-inhibition curves in an experiment for a given drug but different preparations were used in experiments (a) and (b). Values are means and standard errors for four $(a)$ or seven $(b)$ experiments. The control immunologically induced releases of histamine were $33.7 \%(8.2 \%)(a)$ and $28.1 \%(5.9 \%)(b)$ of the respective totals. ${ }^{*} p<0.05,{ }^{* *} p<0.001$ (paired t test). 

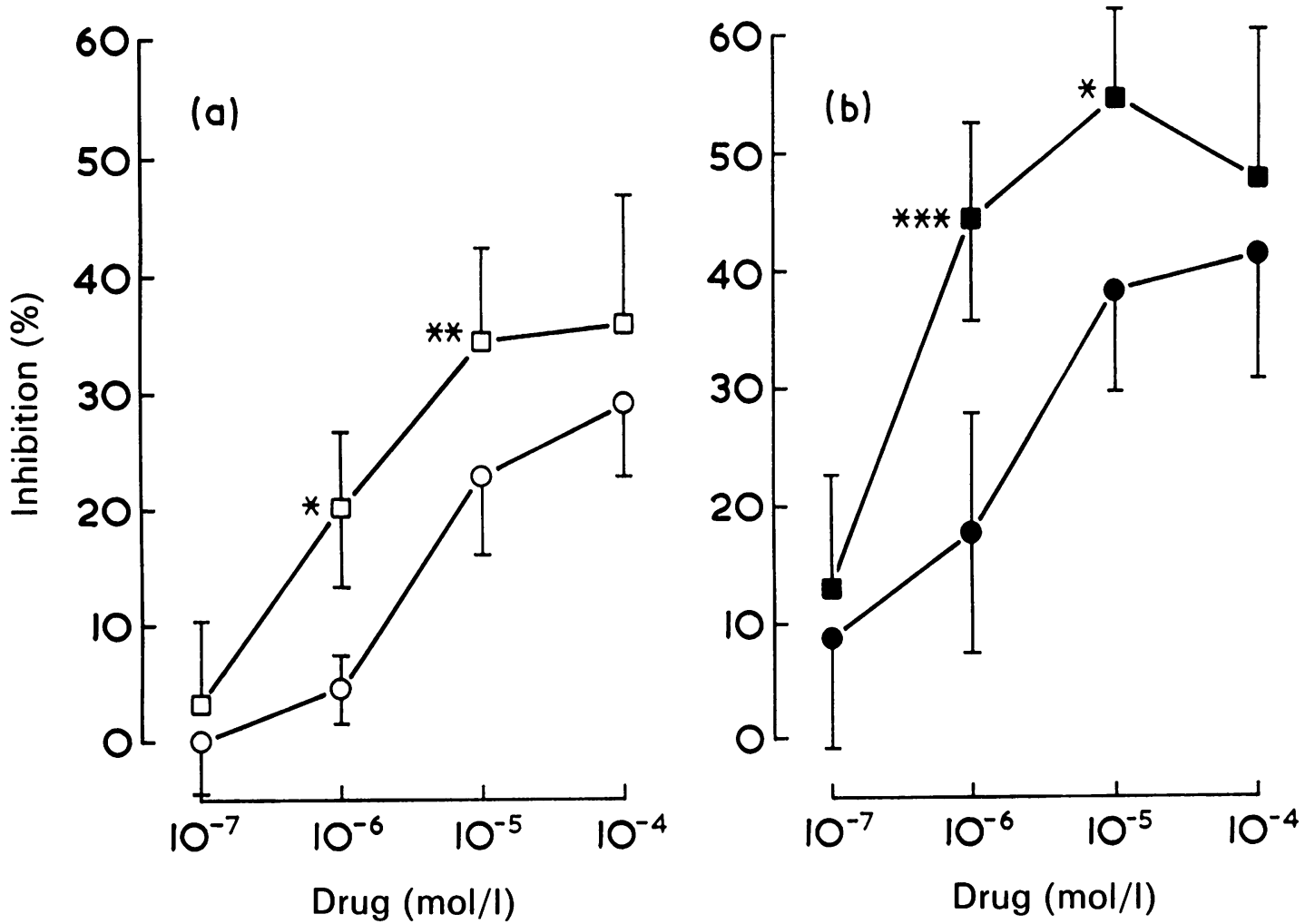

Fig 3 Effect of sodium cromoglycate ( $O, O)$ and nedocromil sodium ( $\square, \square$ ) on immunologically induced histamine release from (a) dispersed human lung mast cells and (b) human lavage fluid mast cells. The drugs were added to the dispersed lung cells simultaneously with the secretory stimulus (open symbols) or preincubated with the lavage cells for 10 minutes before challenge (filled symbols). In each experiment a single pool of cells was used to construct parallel dose inhibition curves for the two drugs. Values are means and standard errors for eight $(a)$ or five $(b)$ experiments. The control immunologically induced releases of histamine were $24.8 \%(4.9 \%)$ (a) and $21.6 \%(4.9 \%)$ (b) of the respective totals. ${ }^{*} p<0.05,{ }^{* *} p<0.01$, $* * * p<0.001$ (paired t test).

induced secretion (see below) the $\mathrm{IC}_{30}$ values (the concentrations required to produce $30 \%$ inhibition of release) for lavage and parenchymal cells were, respectively, $0.52(0.11)$ and $5.7(1.4) \mu \mathrm{mol} / 1$ for nedocromil sodium $(\mathrm{p}<0.01$, immunologically induced histamine releases $23 \cdot 2 \%(3 \cdot 3 \%)$ and $22 \cdot 4 \%(4 \cdot 2 \%))$ and $7 \cdot 1 \quad(0.7)$ and $422(132) \mu \mathrm{mol} / 1$ for sodium cromoglycate $(p<0.01$, immunologically induced histamine releases $23 \cdot 2 \%(3 \cdot 3 \%)$ and $24 \cdot 1 \%(3.0 \%)$ ).

Nedocromil sodium and sodium cromoglycate also inhibited histamine release from lavage cells of five patients with sarcoidosis and in three patients with extrinsic asthma (fig 4). Nedocromil sodium was again more active than sodium cromoglycate, though both drugs were apparently less potent than when they were used on cells from normal control subjects (fig 3 ). This effect may reflect the hyperreactivity of mast cells from patients with sarcoidosis and asthma and the corresponding increase in the concentrations of induced histamine secretion (see below).

\section{Discussion}

We have shown that sodium cromoglycate and nedocromil sodium both inhibited immunologically stimulated histamine release from lavage and isolated lung mast cells. The inhibition was dose dependent, nedocromil sodium being one order of magnitude more potent with both cell populations. Both drugs produced greater inhibition of histamine release from lavage mast cells than from lung parenchymal mast cells. A further difference was the clearcut tachyphylactic effect ${ }^{11} 12$ of both drugs on parenchymal mast cell histamine release and the absence of this effect on lavage cells. In fact, preincubation of lavage cells with the drug often led to increased inhibition of histamine release. Tachyphylaxis is not seen with these drugs in clinical practice, suggesting that the site of action in vivo is the lavage mast cell, which is presumably the first to encounter allergen, rather than the mast cell in the lung parenchyma. Lung parenchymal mast cells 


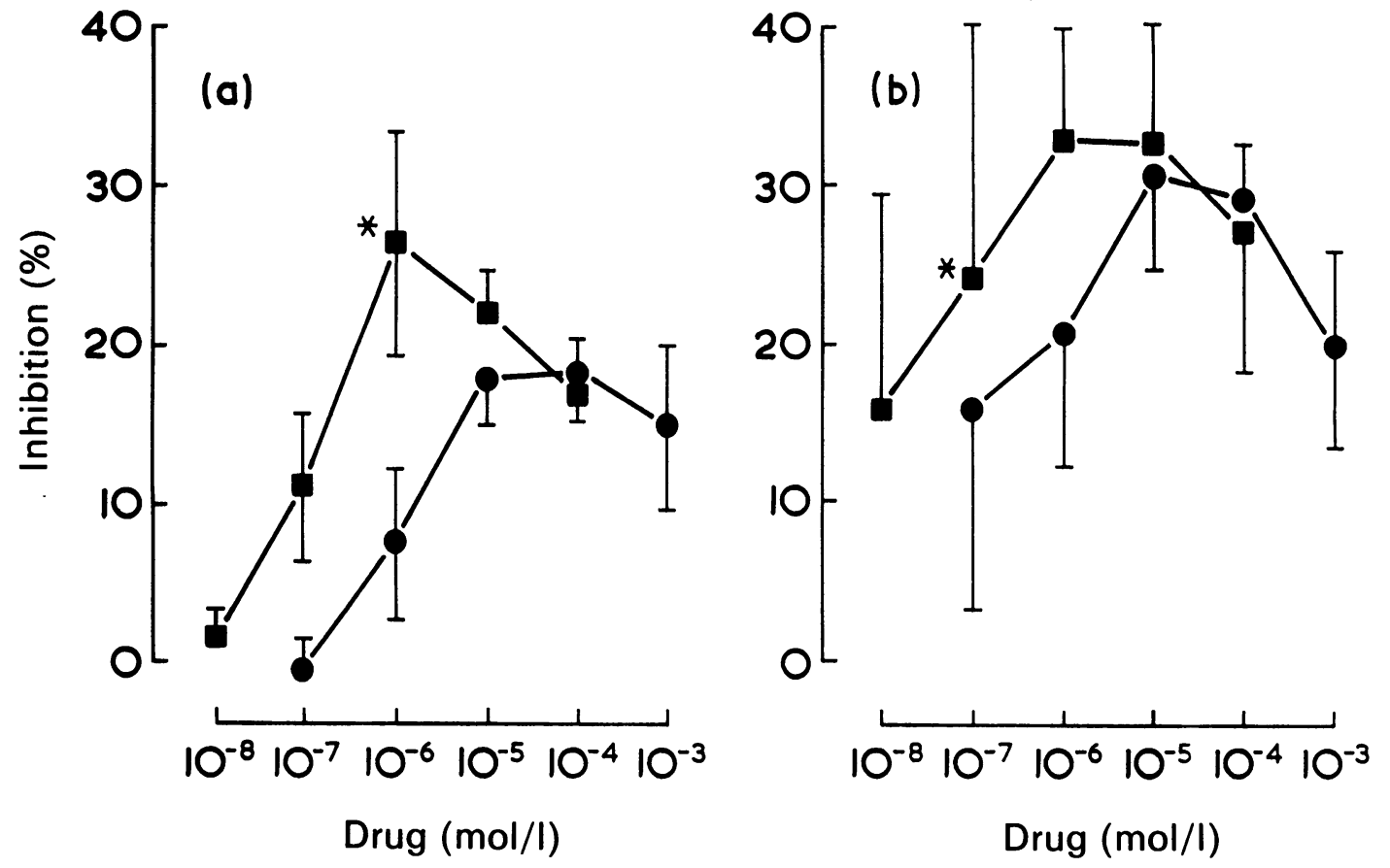

Fig 4 Effect of sodium cromoglycate ( $)$ ) and nedocromil sodium ( $\square$ ) on immunologically induced histamine release from lavage fluid cells of patients with (a) sarcoidosis and (b) extrinsic asthma. The drugs were preincubated with the cells for 10 minutes before challenge. In each experiment a single pool of cells was used to construct parallel dose inhibition curves for the two drugs. Values are means and standard errors for five $(a)$ or three $(b)$ experiments. The control immunologically induced releases of histamine were $36.2 \%(9.5 \%)(a)$ and $39.6 \%(5.0 \%)$ (b) of the respective totals. ${ }^{*} p<0.05$ (paired t test).

may be an inappropriate model system for the study of anti-asthma compounds.

Similar differences in potency between nedocromil sodium and sodium cromoglycate have been reported for mast cells obtained by bronchoalveolar lavage in monkeys sensitised to Ascaris suum..$^{13}$ Considerable care is needed in the design of these experiments, however, because the activity of sodium cromoglycate varies substantially and inversely with the strength of the secretory stimulus. ${ }^{14}$ This effect is apparent in the present study if the maximum inhibition produced by sodium cromoglycate or nedocromil sodium is compared in lavage cells, for example, in individual experiments (figs 2 and 3, table). The apparent activity of both drugs clearly decreases with an increasing level of induced histamine release. It is also important that the control level of immunologically induced secretion is not too high; if it is, the suppression of activity of the test drugs under these conditions may mask differences between the compounds (table).

These points are relevant to the assessment of the likely potencies of anti-asthma drugs in clinical practice. For practical reasons control laboratory studies use immunologically induced releases of histamine in the range $20-40 \%$. Clinically secretion of this magni- tude probably never occurs and the amount of histamine released in a severe attack of asthma is likely to be less than $1 \%$ of the total histamine content of the lung. Given this inverse relation between the activityx of these drugs and the strength of the secretory stimulus, the potency of both nedocromil sodium and sodium cromoglycate when used clinically is likely to윽 be very much greater than that measured in the laboratory.

These considerations make it difficult to compare the relative activities of the test drugs in different systems precisely. In parallel experiments using $N_{\sigma}$ carefully matched levels of secretion, however, both $\mathrm{N}$ nedocromil sodium and sodium cromoglycate were more than one order of magnitude more active against ${ }^{\omega}$ lavage mast cells than against dispersed lung mast cells. These findings extend those of previous studies? showing that the action of sodium cromoglycate is highly tissue and species specific and that the potency: of the drug varies substantially from one mast cell to another. ${ }^{10}$ This effect may be of considerable impor- $\frac{\overrightarrow{\mathrm{D}}}{\mathrm{O}}$ tance given the potential role of lavage mast cells in the $\frac{?}{\mathbb{P}}$ initial pathogenesis of asthma ${ }^{4}$ and the immediate 2 contact of this subpopulation of mast cells with? inhaled drugs. 
Both nedocromil sodium and sodium cromoglycate inhibited histamine release from the lavage cells of patients with sarcoidosis and extrinsic asthma. Both drugs were apparently less potent in the cells from these patients than in those from normal control subjects. Lavage mast cells from patients with either sarcoidosis or asthma are, however, hyperresponsive to immunological challenge, ${ }^{45}$ and our findings may be a reflection of the increased level of induced histamine secretion in these cells rather than any fundamental differences between the mast cells in the disease states. Further studies of asthmatic patients with individual titration of their response to immunological challenge would be required to resolve this question.

This work was supported by grants from the Asthma Research Council, Fisons PLC (pharmaceutical division), the Jules Thorn Trust, and the Wellcome Trust. Some of these data have been previously reviewed ${ }^{16}$ and are incorported here with the permission of Springer-Verlag (London).

\section{References}

1 Kay AB. Mediators and inflammatory cells in asthma. In: Kay AB, ed. Asthma: clinical pharmacology and therapeutic progress. Oxford: Blackwell, 1986:1-10.

2 Robinson C, Holgate ST. Mast cell-dependent inflammatory mediators and their putative role in bronchial asthma. Clin Sci 1985;68:103-12.

3 Flint KC, Leung KBP, Pearce FL, et al. Human mast cells recovered by bronchoalveolar lavage: their morphology, histamine release and the effects of sodium cromoglycate. Clin Sci 1985;68:427-32.

4 Flint KC, Leung KBP, Hudspith BN, et al. Bronchoalveolar mast cells in extrinsic asthma: a mechanism for the initiation of antigen specific bronchoconstriction. Br Med J 1985;291:923-6.
5 Flint KC, Leung KBP, Hudspith BN, et al. Bronchoalveolar mast cells in sarcoidosis: increased numbers and accentuation of mediator release. Thorax 1986;41:94-9.

6 Pearce FL, Flint KC, Leung KBP, et al. Some studies on human pulmonary mast cells obtained by bronchoalveolar lavage and by enzymic dissociation of whole lung tissue. Int Arch Allergy Appl Immunol 1987;82:507-12.

7 Leung KBP, Flint KC, Brostoff J, et al. A comparison of nedocromil sodium and sodium cromoglycate on human lung mast cells obtained by bronchoalveolar lavage and by dispersion of lung fragments. Eur $J$ Respir Dis 1986;69(suppl 147):223-6.

8 Bienenstock J, Befus AD, Pearce FL, et al. Mast cell heterogeneity: derivation and function, with emphasis on the intestine. J Allergy Clin Immunol 1982;70:40712.

9 Pearce FL, Ali H, Barrett KE, et al. Functional characteristics of mucosal and connective tissue mast cells of man, the rat and other animals. Int Arch Allergy Appl Immunol 1985;77:274-6.

10 Pearce FL. On the heterogeneity of mast cells. Pharmacology 1986;32:61-71.

11 Church MK. Cromoglycate-like anti-allergic drugs: a review. Drugs of Today 1978;14:281-341.

12 Church MK, Young KD. The characteristics of inhibition of histamine release from human lung fragments by sodium cromoglycate, salbutamol and chlorpromazine. Br J Pharmacol 1983;78:671-9.

13 Eady RP, Greenwood B, Jackson DM, et al. The effect of nedocromil sodium and sodium cromoglycate on antigen-induced bronchoconstriction in the Ascarissensitive monkey. Br J Pharmacol 1985;85:323-5.

14 Pearce FL, Rafii-Tabar E. Inhibition by disodium cromoglycate of anaphylactic histamine secretion from rat peritoneal mast cells in the presence of phosphatidylserine. Agents Actions 1983;13:212-5.

15 Pearce FL. Calcium and histamine secretion from mast cells. Prog Med Chem 1982;19:59-109.

16 Flint KC. Bronchoalveolar mast cells and asthma. London: Springer, 1987:1-84. 